\title{
Enhancing Students’ Drama Performance: A Process Approach
}

\author{
Syamsul Bahri ${ }^{1}$, Meisuri ${ }^{2}$ \\ Universitas Negeri Medan, Medan, Indonesia \\ meisuriw@yahoo.com
}

\section{Abstract}

This research aims at describing and developing website based authentic assessment model on drama course in English literature study program. The research data comes from descriptive information of the experts or validator along with the suggestion from the students as the product user through the PBL activity combined with the observation and recording with video tape. Data analysis is done by using rubric measure: a) the information completeness which is applied on the work sheets. b) the information comprehensiveness which is included in the paragraph written by the students. The overall of the flow diagram are : Preparation: choosing the research based article which is relevant with the course; preparing worksheet and observation sheet. Implementation: the students read the research based article and fill in the worksheet. . Observation: filling in the observation sheet and writing anecdotal record. Reflection: analyzing the observation sheet and measurement rubric. With the implementation of authentic assessment toward the students who participate in the drama appreciation course. The obtained results show significant increase in their competence through the 6 kinds of task which contain website based authentic assessment on the stage of manipulating expression, scripting, dialogue reading, pre performing and stage performance.

Keywords

English language

competence; authentic assessment; website; drama appreciation

\section{Introduction}

The change of element in the standard content of KKNI 2013 curriculum encourages the lecturers who tend to use traditional and structural assessment, and assignment have to change their assessment to become an authentic one. Authentic assessment is an assessment which is done comprehensively to measure the input, process, and output of a learning which focus is not just in knowledge through output assessment but also based on the skill through process assessment, authentic assessment, and output assessment in a total and whole way. (Mulyasa, 2013; Suwandi, 2010; Rahmawati, 2013).

Based on the observation and discussion with the lecturers and students in English literature study program, it is found that the regulation which have been made by the institute leader concerning about the education process of the 6 task system which has been used by the lecturers has yet to fully utilize the electronic media which are available in campus. Because of that, it is time for the lecturers to improve the study result of the students by authentic and effective measurement system to get the results which are better, easier, more valid, and most importantly can measure the true ability of the students.

Authentic measurement has a weakness. Which is, the need of special place to contain documents (students' works) which can lead to the piling up of books. To solve that problem, website based authentic assessment media can become an alternative solution for that problem. This kind of authentic assessment is called website based authentic assessment, it is an authentic assessment document which is saved in electronic format and connected with the 
internet. With the advancement of information technology nowadays, every student can save and present their writings, assignments, multimedia presentation in the shape of text, graphic, sound, and video in one and interconnected document.

KKNI curriculum 2013 demands the achievement of 3 competences, cognitive, affective, and rational psychomotor. That is why, the precise action is needed to improve the students' study result, and alternative which can be done with problem based learning model. According to Arends (2008), problem based learning is a study model which uses authentic problem approach so that the students can built their own knowledge, grow a higher skill and inquiry, make them independent, and increase their self-confidence. The implementation of website based assessment will be done well, because the class and campus have provided the facilities and infrastructure for the implementation that can be seen in the shape of language lab and computer along with internet connection that can be accessed easily.

On the early implementation stage of website based authentic assessment, this research will focus on Drama Appreciation subject. Drama Appreciation subject not only demand theoretical mastery of the students, but more than that they must be competent in every other psychomotor skill, such as in the 4 language skills (listening, reading, speaking, and writing), and performance skill such as mimic, voice, style, and staging management. To reach systematic study and measurable assessment (reliable) then the website based authentic assessment is used and implemented in the 6 assignments which have been set by the head of UNIMED or MSU (Medan State University) which has been done and implemented since the study year of 2016/2017 those 6 kind of assignments such as routine assignment (RA), Critical Journal Review (CJR, Critical Book Review (CBR), Engineering Idea (RE), Mini Research (MR), and Project (PR).

The goal of this research is to develop the website based authentic assignment as the chain of assessment process which should be done by the lecturers and students in the college subject of drama and others. Specifically, this research is directed to find the best solution in college subject related to literary review which naturally should be directed toward the achievement of language and performance competence beside in improving the affection toward the national and local literary works as the richness of Indonesian soul and culture. Generally, the result of his discussion can also be adopted into other subjects beside literary subject, and modified according to the main focus of the subject. But still in the utilization of technology or website based authentic assessment.

a. This research will be directed into two focus which are related to each other. They are related to the language skill achievement process (Listening, Reading, Speaking, and Writing) along with the focus of literature (Drama) which is combined into PBL learning method (Problem Based Learning).

b. Through this research, it is expected that the collected data can give illustration and contribution toward the development of theory, application, or policy in website based authentic assessment especially toward the drama subject, and it is expected to be implementable on other subjects in study program, English language major, even toward other knowledge discipline outside English language and literature.

c. In the researcher community order, this suggested study is directed to give clear overview how assignment selection process and website based authentic assessment decision can be socialized in FGD English study program lecturers 
The result of this research also expected to implication in policy maker that become the guide in study program development in students coaching /students in effective study process.

\section{Review of Literature}

\subsection{Assessment in Study Process}

Assessment pressure in 2013 curriculum or KKNI is authentic assessment where in doing the assessment toward the result of the students' study is seriously paying attention toward authentic assessment, beside data gathering that can give the overview toward students' study development.

Authentic assessment is toward the balance between the assessment of attitude competence, knowledge, and skill that are matching with characteristic development of the students corresponding with their level.

\section{Features and Characteristic of Authentic Assessment}

Some special features of this assessment is; it is imperative to measure all of learning aspects during or after the process is done with using certain technique and tool which focus on the depth of knowledge and mastery of certain competence (Kunandar, 2013). Authentic assessment can be done to measure competence achievement toward one or several basic competence (formative) or even can be done toward standard competence or main competence in one semester such as skills and performance and done continuously by considering the feedbacks.

\subsection{Website}

In digital era nowadays, we are consciously or eve unconsciously have been faced with any kind of technology that can help the lecturers and students to access the study material without being limited by space and time. Electronic media such as laptop, computer, cellphone, tablet, and social media like twitter, blog, whiteboard, white paper, and other virtual media which have given freedom for the students to get information about their study material, and it is also expected to be useful to improve the quality of assignment working process, and the assessment of the end result of that subject. Furthermore, it can give benefit toward the two parties, lecturer and student in improving the learning quality.

In doing authentic assessment toward college subject, it needs tool or media that can accommodate every or some documents even for assignment or assessment that has been arranged authentically. The used electronic media can be directed to connect them authentically with the experts in the subjects and some local, national, or even international organization which are relevant with the knowledge discipline which follow the trend, it can even open communication network which involves every scientific side openly and globally.

\section{Research Method}

The method which is used is descriptive qualitative method which can be considered as problem solving procedure which is investigated by picturing the condition of the research object in the present time based on the facts which are visible or how it is should be (Nawawi, 1998:63). This website based authentic assessment is designed with adapting plomp model (2007) which consists of three phases, they are: preliminary phase, prototyping, and assessment phase, which implementation is combined with problem based study model 
(problem-based learning). Study model of problem based learning (PBL) covers five phases, such as orientation toward problem, organize, guide, and evaluate problem solving process.

The type of this research data is descriptive-qualitative data. Descriptive data is collected from respond or repair suggestion master validator of the material, media expert validator, study validator (senior lecturer) and the students (product user) along with descriptive data website based authentic assessment document as authentic assessment. Quantitative data with simple statistic is collected from questionnaire score result which are spread to validator team and product user. This research in UNIMED campus, especially in Drama subject class, digital library, and language laboratory, along with the culture park of Medan, especially in the training process and product performance in odd semester 2017/2018.

\section{Discussion}

\subsection{Mimicary}

Character making process or character creation of every drama that will be presented begins with the mimicary training where every student exercises the expression in the character starting from the expression of happy, sad, angry, confused, amazed, and wonder which are trained by all of the students and recorded it. In every expression, the students will first create situation context which will be expressed and recorded to be a mimicary video. The situation context for example is, the angry expression in the context that a student who is angry because have been tricked by his/her classmate and other face expression situation context. This expression video made by the student is e-mailed to the subject lecturer and the hard copy of the expression is submitted too.

The lecturer activity in presenting the mimicary video in front of the class discuss, criticize, and give suggestion to the lack of expression which is shown for further repair. If an unqualified mimicary expression video is found then, the student is required to remake their face (expression) video until they got a better one.

This assignment about mimicary face expression is submitted in the shape of video and hard copy is included in Routine Task (RI) and must be done, beside worksheet which must be answered every drama appreciation class meeting. To completing the subject and knowledge about drama character, passion, expression, and stage equipment, the students are also tasked to review journal which is related to important things in drama. That journal is taken from internet and decided for each of the students and the soft copy of that journal is emailed to the lecturer and each of the students review the journal which related to drama according to the format that has been decided. This is the assignment of CJR (Critical Journal Review).

\subsection{Scripting}

Drama Appreciation subject class SAS 16 B which consist of 34 students divided into 3 drama groups which will be performed. Those three groups will cover:

a. International standard drama with the title "Streetcar Named Desire"

b. national standard drama with the title "Opera Van Oranje"

c. drama with the trait to expose local culture "Sangkuriang"

because this research is based on website, then every group is asked to make their own email, to review each other groups through e-mail. Every group read and understand the original drama script from each group that has been decided. After reading and understanding 
each of those original drama script then they must make drama script with their own language with the duration of 20 minutes to be performed. Drama script which has been made by each groups is the Engineering Idea which is poured with the use of beautiful language such as the use of metaphor words to decorate the dialogues in the drama script. At the Engineering Idea in this language, the students must be able to filter words to match the content of the of the drama with the aim to beautify the language of the dialogues which will be performed. This is part of the 6 assignments from the KKNI curriculum which is the Engineering Idea (RI). The drama script which has been reviewed by each of the groups are submitted back to the lecturer to be reviewed again through e-mail. After the drama script from those three groups have been reviewed by the lecturer, then they will be sent back to each of the groups.

\subsection{Dialogue Reading}

In the fifth meeting, each groups do the process of dialogue reading process with looking their own drama script text. Dialogue reading which be done by each of the groups must have the duration of 20 minutes in maximum. Every groups are filmed and the video is sent to each of the student's groups in order to evaluate their performance through dialogue reading. Every groups performing in dialogue reading process at drama training in front of the class, are given opinions, critics, and suggestions to construct each of the drama groups to be better. In this dialogue reading, the students train their pronunciation, intonation, volume, rhythm, and the understanding of the text which is spoken. Dialogue text understanding is very important because it will affect the expression quality, passion which matched the context, situation and character which are performed. That is why the students have been given the Critical Book Review (CBR) beforehand which trains the students in understanding and review a chosen drama book. The result of this CBR assignment is submitted in the shape of report which has been binded and the softcopy must be sent through e-mail.

\subsection{Pre Performing}

Before the students do peer performance, they must do the Mini Research (MR) assignment where they must watch a live drama/theater show. In this activity, the students must precisely see and observe the important thing related about the staging of a drama. They must find a problem of what they have seen from a drama performance which can be made into a small scale research object, Mini Research (MR). This Mini Research report is binded and submitted along with the softcopy e-mailed to the lecturer. The subject and knowledge that they got from this Mini research (MR) can enrich their knowledge and skill in preparing a drama performance. In drama training performance of every groups held peer performing, which is:

\section{a. Indoor Performing (Class Activity)}

The sixth meeting of the drama appreciation subject is doing peer performing training process for every groups without looking at text script. Every drama groups that performed in front of the class is filmed and the video is sent to the lecturer's e-mail

b. Out Door Performing (Out Door Activity)

Beside the drama performance activity in the class, smoothing the dialogue, strengthening mimicary, characterization and passion then every drama group is asked to train outside of class 2 or 3 times a week, at least 2 times a week. The video of training outside of class is also submitted and e-mailed to the lecturer, then presented. It will naturally show individuals who are discipline, alert, responsible, and individual who have high motivation inside each of the groups. From the presentation of this training video the lecturer 
and students will find the problems and lacking in each of the drama groups that must be fixed at the next trainings. Every training outside of the class, each of the groups have to record their performance. To create a disciplined process and develop a shared responsibility in each of the groups, then the leader of each groups must make a list of attendees for every member of each of their own group

\subsection{Staging Performance}

Huge presentation which is done on the stage is the student's Project Assignment (PR). Before that, the students from every drama groups must have already prepared things which related to the performance, they are: stage background, stage, costume, stage equipment and music corresponding with the type of drama that will be performed. Every drama groups perform a drama that has been decided with the duration of 20 minutes, then it will be evaluated and scored by 4 lecturers as the juries.

From the evaluation and scoring which has been done by the juries, then the best drama groups 1,2 , and 3 is chosen. Every performing drama groups is recorded and filmed. The drama performance videos from each groups are uploaded into youtube that will later become example or reference for the students who take drama appreciation subject for the next semester.

\section{Conclusion}

In doing authentic assessment toward college subject, it needs tool or media that can accommodate every or some documents even for assignment or assessment that has been arranged authentically. The used electronic media can be directed to connect them authentically with the experts in the subjects and some local, national, or even international organization which are relevant with the knowledge discipline which follow the trend, it can even open communication network which involves every scientific side openly and globally.

With doing authentic assessment process towards the students who participate in the drama appreciation subject, the collected result shows improvement in their competence through 6 kind of assignment which also consist of website based authentic assessment inside it in the phase of mimicary, scripting, dialogue reading, pre performing, and stage performance.

Table 1. Recap of Results of 6 Kind of Assignments

\begin{tabular}{|c|l|l|c|}
\hline No. & \multicolumn{1}{|c|}{ Kind of Assignments } & \multicolumn{1}{c|}{ Information } & Score Range \\
\hline 1 & Routine Assignment & Mimicary & 81.05 \\
\hline 2 & Critical Journal Review & Mimicary & 82.86 \\
\hline 3 & Critical Book Review & Dialogue Read & 84.59 \\
\hline 4 & Engineering Idea & Scripting & 86.48 \\
\hline 5 & Mini Research & Pre Perfoming & 88.68 \\
\hline 6 & Project & Staging Perfoming & 92.77 \\
\hline & Total & & 86.07 \\
\hline
\end{tabular}




\section{References}

Arends, R. I. 2008. Learn to Teach. Yogyakarta: Pustaka Belajar Bowo

Mulyasa. 2013. Pengembangan dan Implementasi Kurikulum 2013. Jakarta: Rosda.

Rakhmawati, I., Sriyati, S. \& Widodo, A. 2013. Implementation Of Electronic Portfolio Assessment For Improving Habits Of Mind And Conceptual Understanding Of Biology Education Student. Proceeding International Seminar on Mathematics, Science, and Computer Science Education. ISBN 978-60595549-2-2, UPI Bandung, 13 Oktober 2013.

Sufanti, Main, dan Laili E. Rahmawati. 2012. Teori Evaluasi pengajaran Bahasa dan Sastra Indonesia. Surakarta: FKIP UMS

Suwandi, Sarwiji. 2010. Model Assessment dalam Pembelajaran. Surakarta: Yuma Pustaka. 